Published in final edited form as:

Autism Res. 2013 June ; 6(3): 212-220. doi:10.1002/aur.1280.

\title{
Letting a typical mouse judge whether mouse social interactions are atypical
}

\author{
Charisma R. Shah ${ }^{1}$, Carl Gunnar Forsberg ${ }^{1}$, Jing-Qiong Kang ${ }^{2}$, and Jeremy Veenstra- \\ VanderWeele ${ }^{1,3}$ \\ ${ }^{1}$ Department of Psychiatry, Vanderbilt University \\ 2Department of Neurology, Vanderbilt University \\ ${ }^{3}$ Departments of Pediatrics and Pharmacology; Treatment and Research Institute for Autism \\ Spectrum Disorder, Vanderbilt Kennedy Center for Research on Human Development; Vanderbilt \\ Brain Institute, Vanderbilt University
}

\begin{abstract}
LAY ABSTRACT—Diagnosis of an autism spectrum disorder (ASD) requires a qualitative assessment of social aptitude: one person judging whether another person interacts in a 'typical' way. Quantitative or computerized assessment of social aptitude cannot substitute for this subjective judgment. We hypothesized that mice could be used to make a similar judgment if they prefer 'typical' over 'atypical' social interactions with mouse models relevant to ASD. We used typical C57BL/6 (B6) mice as 'judges' and evaluated their preference for a chamber containing a 'typical' or an 'atypical' mouse. For our atypical mice, we chose two strains with welldocumented social phenotypes, as well a mutant line with abnormal social behavior and seizures. Overall, we observed a characteristic pattern of behavior over the course of 30 minutes, with the judges preferring the typical mouse chamber to the atypical mouse chamber during the last 10 minutes of the test. When we evaluated the individual stimulus pairings, two of the three showed a similar pattern as the overall results, and the other stimulus comparison showed a trend for a preference for the typical mouse chamber across the entire test. We repeated the experiments using the 129S6 strain of typical mice as judges and found a much less strong preference pattern across time. These data suggest that a characteristic pattern of exploration in B6 mice can distinguish some socially atypical animals from controls.
\end{abstract}

SCIENTIFIC ABSTRACT—Diagnosis of an autism spectrum disorder (ASD) requires a qualitative assessment of social aptitude: one person judging whether another person interacts in a 'typical' way. We hypothesized that mice could be used to make a similar judgment if they prefer 'typical' over 'atypical' social interactions with mouse models relevant to ASD. We used wildtype C57BL/6 (B6) mice as 'judges' and evaluated their preference for a chamber containing a 'typical' (B6 or 129S6) or an 'atypical' mouse. For our atypical mouse stimuli, we chose two inbred strains with well-documented social phenotypes (BTBR and BALB/c), as well a mutant line with abnormal social behavior and seizures (Gabrb3+/-). Overall, we observed a stimulus by time interaction ( $\mathrm{P}<0.0001)$, with B6 mice preferring the typical mouse chamber during the last 10 minutes of the 30-minute test. For two of the individual stimulus pairings, we observed a similar chamber by time interaction (BALB/c vs. $129 \mathrm{~S} 6, \mathrm{P}=0.0007$; Gabrb3 $+/-$ vs. $129 \mathrm{~S} 6, \mathrm{P}=0.033$ ).

Correspondence to: Jeremy Veenstra-VanderWeele, M.D., 7158 Medical Research Building III, $46521^{\text {st }}$ Ave S, Nashville, TN, 37232-8548, Phone: 615-936-1701, Fax: 615-936-7475, j.vvw@ vanderbilt.edu.

Conflicts of Interest:

The authors have no direct competing financial interests. JV receives research funding for non-overlapping work from Seaside

Therapeutics, Roche Pharmaceuticals, Novartis, and Forest. 
For the third stimulus pairing, we found a trend for preference of the typical mouse across time (BTBR vs. $\mathrm{B} 6, \mathrm{P}=0.051$ ). We repeated the experiments using $129 \mathrm{~S} 6$ mice as judges and found a significant overall interaction $(\mathrm{P}=0.034)$, but only one stimulus pairing reached significance on its own $(\mathrm{BALB} / \mathrm{c}$ vs. $129 \mathrm{~S} 6, \mathrm{P}=0.0021)$. These data suggest that a characteristic pattern of exploration in B6 mice can distinguish some socially atypical animals from controls.

\section{INTRODUCTION}

Diagnosis of an Autism Spectrum Disorder (ASD) requires a qualitative assessment of impaired social interaction: one human judging whether another human's social behavior is 'atypical' (American Psychiatric Association, 2000). Even the Autism Diagnostic Observation Schedule (ADOS), which incorporates a standardized series of social interactions, still relies on the examiner's qualitative assessment of a child's behavior (Lord, et al., 2000). Thus far, computerized assessments, biomarkers, or other quantitative measures are not used to refine, or even to complement, behaviorally based diagnosis (Veenstra-VanderWeele \& Blakely, 2012; Volkmar, et al., 2009; Zwaigenbaum, et al., 2009). This dependence upon human evaluation of human social behavior presents significant challenges when attempting to evaluate autism-relevant behavior in lower organisms (Ey, et al., 2011; Moy \& Nadler, 2008; Silverman, et al., 2010).

Studies of genetic, prenatal, and perinatal risk have identified a number of ASD susceptibility factors that can be studied in lower organisms (Betancur, 2011; Devlin \& Scherer, 2012; Gardener, et al., 2009, 2011; Guinchat, et al., 2012; State \& Levitt, 2011). Mouse models of ASD susceptibility are appealing for several reasons, including the tractability of genetic manipulation in mice, the relatively short reproductive cycle and time to maturity, and the tendency of mice to live in social groups (Ey, et al., 2011; Moy \& Nadler, 2008; Silverman, et al., 2010). A number of assays have been developed to evaluate the social behavior of mouse models of autism susceptibility (Bolivar, et al., 2007; Crawley, 2007; Moy \& Nadler, 2008; Moy, et al., 2004; Panksepp \& Lahvis, 2007; Pobbe, et al., 2010; Roullet, et al., 2010; Silverman, et al., 2010; Spencer, et al., 2005; Wrenn, et al., 2003). Some of these assays, such as the resident-intruder test or observations of juvenile play, require individual behaviors to be hand-scored by a human observer during dyadic interactions (McFarlane, et al., 2008; Winslow \& Miczek, 1983). Although these direct assays of social behavior might be more sensitive to abnormal social behavior than more automated tests (Pobbe, et al., 2010; Yang, Bozdagi, et al., 2012), they are very timeintensive, their methods are difficult to standardize across labs, and observed differences in individual behaviors can be difficult to interpret.

The most used mouse social assay is a sociability/social approach task that assesses a mouse's preference for a social stimulus (another mouse) over a non-social stimulus over 110 minutes (Kwon, et al., 2006; Moy, et al., 2004; Sankoorikal, et al., 2006; Winslow, 2003). Various versions of this assay have been used in the literature, with most groups now converging on a 10-minute, three-chamber version developed by the Crawley lab (Moy, et al., 2004). This assay has the advantage of being brief, objective, easily quantified, replicable across labs, and responsive to drug treatment (Chadman, 2011; Gould, et al., 2011; Silverman, Oliver, et al., 2012; Silverman, Smith, et al., 2012; Yang, Silverman, et al., 2011). Despite the simplicity and appeal of this test, lack of preference for social stimuli is not a cardinal symptom of autism. Instead, lack of social interest is confined to a subgroup of children described as 'aloof' by Lorna Wing and others, comprising 36-40\% of ASD (Beglinger \& Smith, 2005; Castelloe \& Dawson, 1993; O’Brien, 1996; Wing \& Gould, 1979). Further, this task is dependent upon activity level (Moy, et al., 2009; VeenstraVanderWeele, et al., 2012; Yang, et al., 2009) and may be sensitive to anxiety-like behavior (Peca, et al., 2011; Silverman, et al., 2010). 
The core social symptom in ASD is not a deficit in social interest but in social reciprocity or social aptitude (American Psychiatric Association, 2000). Since we have not been able to quantify social aptitude in humans or program a computer to recognize social deficits, it is unreasonable for us to expect that humans will easily recognize impaired social aptitude in mice. One alternative might be to let a typical mouse judge the social aptitude of a mutant animal. In theory, a mouse 'judge' might be trained to distinguish a mouse with typical or atypical social behavior in an operant paradigm. We hypothesized, however, that a mouse would show a natural preference for a typical social interaction vs. an atypical social interaction. We sought to harness this hypothesized preference in a modification of the three-chamber social paradigm, the Preference for Typical Social Interaction Test (PTSIT), where typical mice are given the choice of spending time near a control mouse versus a mouse that humans have judged to have atypical social behavior.

In evaluating the hypothesis that mice may show a preference for typical social interactions, we sought to incorporate the elegant simplicity of the three-chamber design as developed by the Crawley lab. This design is usually applied in a 10-minute test, but we chose to implement a 30-minute test instead. We reasoned that the initial period of social contact might be driven by interest in the novel aspect of the social stimuli, but that the animal's choices over an extended time would reflect true preference for a typical social interaction. The Paylor lab's observation of altered patterns of social exploration over time in the Fmr1 null mouse supported the idea that different lengths of testing may reflect different motivations (Spencer, et al., 2005).

For stimulus animals, we chose inbred strains that have shown robust and consistent deficits in social behavior across multiple labs. The BTBR T+tf/J (BTBR) mice are the best-studied mouse model of autism-like behavior and show abnormalities in sociability, in juvenile play, and in vocalization across multiple labs (Bolivar, et al., 2007; Gould, et al., 2011;

McFarlane, et al., 2008; Pobbe, et al., 2010). The BALB/c mice similarly show abnormalities in sociability across multiple labs and also show elevated anxiety-like behavior (Jacome, et al., 2011; Moy, et al., 2007; Panksepp \& Lahvis, 2007; Sankoorikal, et al., 2006). Finally, we chose to evaluate the PTSIT using another putative model of ASD, the Gabrb3 hemizygous mouse (Gabrb3+/-), which has frequent absence-like seizures that we would expect would lead to atypical social behavior (DeLorey, et al., 1998; DeLorey, et al., 2008; Homanics, et al., 1997). Further, while mice with complete absence of Gabrb3 frequently die before adulthood, surviving animals have social deficits and have been proposed as a model of autism based upon findings in some but not all autism genetic studies (Buxbaum, et al., 2002; Cook, et al., 1998; Curran, et al., 2005; Delahanty, et al., 2010; Maestrini, et al., 1999; Martin, et al., 2000; McCauley, et al., 2004; Nurmi, et al., 2003; Salmon, et al., 1999; Shao, et al., 2003).

For each comparison, we sought to ask 'typical' C57BL/6 animals to choose to spend time in the chamber with either a mouse with atypical social behavior or a typical control mouse. We then sought to evaluate whether a second 'typical' mouse strain, 129S6/SvEvTac would show a similar pattern of preferences. In both cases, we used modest sample sizes $(n=10)$ to prioritize very large effect sizes that would indicate a useful method to differentiate between typical and atypical social behavior. We chose a repeated measures ANOVA of time in each chamber as our primary analysis to match the hypothesis that mouse 'judges' would spend more time with a 'typical' versus an 'atypical' stimulus animal during the later portions of the test. 


\section{METHODS}

\section{Mice}

All animal procedures were in accordance with the National Institutes of Health Guide for the Care and Use of Laboratory Animals and were approved by the Vanderbilt University Institutional Animal Care and Use Committee. C57BL/6 (B6, Harlan Teklad, Indianapolis, IN), 129S6/SvEvTac (129S6, Taconic Farms, Germantown, NY), BTBR T+tf/J (Jackson Laboratories, Bar Harbor, ME), and BALB/c (Taconic Farms, Germantown, NY) males were obtained at 6-8 weeks of age. Gabrb3 +/- breeders (Homanics, et al., 1997) were acquired from Jackson Laboratories (Bar Harbor, ME) on a mixed C57BL/6-129S6 genetic background, and male progeny were used after 8 weeks of age. Animals were housed 3-5 mice per cage by strain in the behavioral animal facility; standard rodent chow and water were available ad libitum. All animals were allowed to acclimate to the colony room for one week and were at least 8 weeks old before testing.

\section{Preference for Typical Social Interaction Test}

As a modification of the well-developed three-chamber social tests, preference for typical social interaction was measured in a three-chamber polycarbonate apparatus with sliding doors separating each chamber, as previously described (Carter, et al., 2011). Ten B6 and ten 129S6 males were designated as "judge" mice. The remaining 5 B6, 5-129S6, 5 BTBR, $5 \mathrm{BALB} / \mathrm{c}$, and $5 \mathrm{Gabrb3}+/-$ mice were designated as "stimulus" mice.

Prior to experimentation, stimulus mice were allowed to habituate to inverted wire pencil cups (Organize It, Citrus Heights, CA) placed in the three-chamber box in the testing room for 45 minutes, twice a day for 3 consecutive days. Between each habituation session, the chamber and pencil cups were cleaned with MB-10 chlorine dioxide antimicrobial solution (Quip Labs, Wilmington, DE) and then 70\% ethanol. On the day of the experiment, designated judge mice were allowed to acclimate to the testing room for 30 minutes without stimulus mice present. To begin the assay, a judge mouse was placed in the center chamber and allowed to explore the empty 3-chamber box freely for 10 minutes. After this habituation period, the judge mouse was directed to the center chamber and the doors were closed. Two stimulus mice of opposing strains (B6 versus BTBR; $129 \mathrm{~S} 6$ versus BALB/c; 129S6 versus GABA $33 \mathrm{R}+/-$ ) were introduced to the side chambers in the inverted pencil cups. A small weight was placed above the pencil cups to discourage climbing by the judge mouse. The doors were then opened and the judge mouse was allowed to investigate for 30 minutes. Both the habituation and the preference for typical social interaction portion of the assay were video-recorded and scored for side-bias and strain preference using Any-Maze tracking of the mouse's body and nose (Stoelting Co, Wood Dale, IL). "Chamber time" was defined as the judge mouse's body being completely within the side chamber. "Sniff time" was defined as the judge mouse's nose being within $1 \mathrm{~cm}$ of either of the inverted pencil cups. Upon completion of the assay, the judge and stimulus mice were returned to their respective home-cages. The 3-chamber box, doors, pencil cups, and weights were cleaned first with MB-10 and then with 70\% ethanol between each judge mouse. All trials of each individual stimulus pairing (B6 versus BTBR; 129S6 versus BALB/c; 129S6 versus GABA $\beta 3 \mathrm{R}+/-$ ) were completed before moving to the next stimulus pairing. The stimulus strains were alternated between the two side chambers (i.e., left then right in subsequent tests) in the apparatus and the individual stimulus mice were rotated between each trial.

\section{Statistics}

Two-way, repeated measures ANOVA with Bonferroni multiple comparison test of time in each side chamber and within $1 \mathrm{cM}$ of each pencil cup was conducted using GraphPad Prism (La Jolla, CA). 


\section{RESULTS}

Neither B6 nor 129S6 'judge' mice showed a significant side preference during the habituation period of the task. The time B6 'judge' mice spent in each chamber showed the hypothesized statistical interaction between stimulus strain and time period for two of the three strain comparisons ( $\mathrm{P}<0.001$ for 129S6 vs. BALB/c and $\mathrm{P}<0.05$ for $129 \mathrm{~S} 6 \mathrm{vs.}$ Gabrb3+/-, Figure 1B, C). For the third strain comparison, B6 vs. BTBR, they showed a trend for overall preference of $\mathrm{B} 6$ across all three time periods $(\mathrm{P}=0.051$, Figure $1 \mathrm{~A})$. When all three typical vs. atypical mouse strain comparisons were pooled, the stimulus strain by time period interaction was highly significant $(\mathrm{P}<0.0001$, Figure 1D). The interaction terms for $\mathrm{B} 6$ time spent within $1 \mathrm{cM}$ of the stimulus mouse were not statistically significant for the individual strain comparisons (Figures $1 \mathrm{E}-\mathrm{G}$ ) but were significant for the pooled typical vs. atypical analysis $(\mathrm{P}<0.05$, Figure $1 \mathrm{H})$.

The time 129S6 'judge' mice spent in each chamber showed the hypothesized statistical interaction between stimulus strain and time period for one of the three stimulus strain comparisons ( $\mathrm{P}<0.01$ for $129 \mathrm{~S} 6$ vs. BALB/c, Figure 2B). Neither of the other stimulus strain comparisons was statistically significant (Figures $2 \mathrm{~A}, \mathrm{C}$ ). The pooled typical vs. atypical strain by time period interaction was statistically significant $(\mathrm{P}<0.05$, Figure 2D). None of the interaction terms for 129S6 time spent within $1 \mathrm{cM}$ of the stimulus mouse was statistically significant, nor was the pooled analysis (Figures 2E-H).

\section{DISCUSSION}

As hypothesized, for two of the three strain comparisons and in the pooled analysis, we observed that B6 mice showed a significant strain by time period statistical interaction in the time they spent in the same chamber with 'typical' versus 'atypical' mice. For the pooled analysis, Bonferroni post-test suggested that the statistical interaction was driven by a preference for spending time in the chamber with the 'typical' mouse in the last 10-minute period of the PTSIT. No significant statistical interactions were seen for time spent within 1 $\mathrm{cM}$ of the pencil cup in any of the comparisons.

The findings for 129S6 judge mice were not as striking as for B6; however one of the strain comparisons and the pooled analysis did reveal a significant strain by time period statistical interaction in the time that they spent in the same chamber with the 'typical' versus 'atypical' mice. Higher variability is also seen for the 129S6 judges, reflecting a tendency for some of these animals to remain stationary for long periods of time after the initial period of exploration (Veenstra-VanderWeele, et al., 2012). Again, no significant interactions were seen for time spent within $1 \mathrm{cM}$ of the pencil cup in any of the comparisons. This suggests that 129S6 mice do not show as strong a preference for chambers containing 'typical' mice.

The pattern of preference for typical social interaction in both the B6 and the 129S6 mice suggests that there may be different motivations for different time periods within the PTSIT. We would hypothesize that the initial 10-minute time period represents social exploration, as reflected in more sniffing behavior during this time period. This time period may not be as dependent upon the stimulus mouse's social behavior as it is dependent upon the presence of a social odor to investigate. Previous findings are consistent with the interpretation that the first 5-10 minutes of the three-chamber task are dominated by olfactory social exploration. Over a 10-minute three-chamber test, the Crawley lab found that B6 mice show no preference for a mouse in an inverted pencil cup over a nestlet containing social odors (Ryan, et al., 2008). Further, they found that B6 mice actually prefer a nestlet containing social odors to a mouse confined in a plexiglass cylinder that is impermeant to odor (Ryan, 
et al., 2008). The Brodkin lab has found that time sniffing an odor-permeant cylinder containing a mouse is a more sensitive and reliable measure than time spent in the chamber with the mouse stimulus across a 10-minute three-chamber test (Fairless, et al., 2011). The significant statistical interaction findings on the PTSIT may indicate that, once the initial social exploration has been completed, mice prefer to spend time in a chamber with a 'typical' over an 'atypical' mouse.

The lack of difference observed in time within $1 \mathrm{cM}$ of the two stimulus animals further suggests that the effects seen for chamber time are not primarily driven by close social exploration or contact. Alternatively, hand scoring of close social contacts between the "judge" and "stimulus" animals could reveal subtle differences in social contacts that cannot be observed by AnyMaze coding of time within $1 \mathrm{cM}$ of the pencil cup. It is possible that the effects seen for chamber time do not reflect differences in time spent in social interaction at all; although further data on vocalizations or olfactory communication would be necessary to assess this more fully. Various interpretations of the chamber time differences are possible. Late in the test, when considerable time has already been available for exploration of the social stimuli, mice may prefer the "typical" chamber because their contacts with the typical mouse have been rewarding in some way, or because they feel safer in the chamber containing a typical mouse, or because the atypical mouse chamber is aversive in some way. Ultimately, these data don't allow a clear distinction between these possibilities, but they do suggest that C57 animals show a different pattern of behavior that may distinguish between "typical" and "atypical" mice.

The Crawley lab has found that B6 mice show preference for multiple inbred mouse strains (B6, BTBR, A/J, 129Sv/ImJ) over a novel object on the 10-minute three-chamber sociability test (Nadler, et al., 2004; Yang, Abrams, et al., 2012). Of further relevance to our findings, they found that B6 mice modulate their contacts with freely moving stimulus animals depending upon the stimulus strain, showing less nose-to-nose sniffing and frontal approach with BTBR in comparison to B6 stimulus animals (Yang, Abrams, et al., 2012).

These initial findings suggest that mice may prefer some social interactions to others, with their preferences following a pattern that other tests differentiate as 'typical' versus 'atypical' for mouse social behavior. There are also some important limitations to these findings. First, we used limited sample sizes that only allow us to detect very large effect sizes. We reasoned that only substantial effect sizes would drive utility of this paradigm for future studies. The effect sizes we actually observed were smaller than those seen for the three-chamber test when comparing a social stimulus to a non-social stimulus. This may reflect the complexities of differentiating social aptitude from social approach behavior. Second, we only evaluated three lines of 'atypical' mice. Further testing could evaluate whether these findings would extend to the broader array of mouse lines with atypical social behavior. Third, we used the same 'judge' animals in multiple experiments, reasoning that this would allow us to evaluate the robustness of the effect across repeated testing. Fourth, we re-used stimulus animals in the assay, which could lead to changes in their behavior; although each "judge" mouse only encountered a stimulus animal a single time. Finally, we did not use littermate comparisons for these experiments, which is not possible for inbred strains of mice. It is therefore possible that the 'atypical' social behavior present in these mouse lines is determined by early social experience, rather than genetic background itself (Yang, Perry, et al., 2011).

These findings also raise interesting questions for future study. We approached the initial experiments as an opportunity to evaluate whether mice show preference for 'typical' versus 'atypical' social interactions. Other approaches to this hypothesis would include free interactions with different strains of mice followed by a conditioned place preference 
approach (Panksepp \& Lahvis, 2007). Turning the paradigm on its head, it may also be possible to evaluate whether particular lines of mice show preference for typical versus atypical social interactions as judges in this paradigm, which could also indicate social aptitude. Our initial findings suggest that B6 animals show more robust preference for 'typical' social interactions than 129S6; although we did not explicitly evaluate this possibility. Overall, our observations suggest that the PTSIT may be a useful addition to a battery of social tests, including the three-chamber sociability test, as well as tests of activity, anxiety-like, and other autism-relevant behavior. Further work will be necessary to evaluate the degree to which it correlates with patterns of mouse free interaction or other potential measures of social aptitude.

\section{Acknowledgments}

Grant sponsor: NIMH; Grant number MH81066

Chris Jetter and Travis Kerr provided technical assistance. Chris Muller provided feedback on the manuscript. Jacqueline Crawley provided behavioral advice. This work was supported by NIH grants MH081066 (JV), and an NIH grants to the Vanderbilt Kennedy Center (HD15052).

\section{References}

American Psychiatric Association. Diagnostic and Statistical Manual of Mental Disorders-Text Revision (DSM-IV-TR). 4. Washington, D.C: American Psychiatric Association Press, Inc; 2000.

Beglinger L, Smith T. Concurrent validity of social subtype and IQ after early intensive behavioral intervention in children with autism: a preliminary investigation. J Autism Dev Disord. 2005; 35:295-303. [PubMed: 16119470]

Betancur C. Etiological heterogeneity in autism spectrum disorders: more than 100 genetic and genomic disorders and still counting. Brain Res. 2011; 1380:42-77. [PubMed: 21129364]

Bolivar VJ, Walters SR, Phoenix JL. Assessing autism-like behavior in mice: variations in social interactions among inbred strains. Behav Brain Res. 2007; 176:21-26. [PubMed: 17097158]

Buxbaum J, Silverman J, Smith C, Greenberg D, Kilifarski M, Reichert J, et al. Association between a GABRB3 polymorphism and autism. Molecular Psychiatry. 2002; 7:311-316. [PubMed: 11920158]

Carter MD, Shah CR, Muller CL, Crawley JN, Carneiro AM, Veenstra-VanderWeele J. Absence of preference for social novelty and increased grooming in integrin beta3 knockout mice: initial studies and future directions. Autism Res. 2011; 4:57-67. [PubMed: 21254450]

Castelloe P, Dawson G. Subclassification of children with autism and pervasive developmental disorder: a questionnaire based on Wing's subgrouping scheme. J Autism Dev Disord. 1993; 23:229-241. [PubMed: 8331045]

Chadman KK. Fluoxetine but not risperidone increases sociability in the BTBR mouse model of autism. Pharmacol Biochem Behav. 2011; 97:586-594. [PubMed: 20863848]

Cook EH Jr, Courchesne RY, Cox NJ, Lord C, Gonen D, Guter SJ, et al. Linkage-disequilibrium mapping of autistic disorder, with 15q11-13 markers. Am J Hum Genet. 1998; 62:1077-1083. [PubMed: 9545402]

Crawley JN. Mouse behavioral assays relevant to the symptoms of autism. Brain Pathol. 2007; 17:448-459. [PubMed: 17919130]

Curran S, Roberts S, Thomas S, Veltman M, Browne J, Medda E, et al. An association analysis of microsatellite markers across the Prader-Willi/Angelman critical region on chromosome 15 (q1113) and autism spectrum disorder. Am J Med Genet B Neuropsychiatr Genet. 2005; 137B:25-28. [PubMed: 15952184]

Delahanty RJ, Kang JQ, Brune CW, Kistner EO, Courchesne E, Cox NJ, et al. Maternal transmission of a rare GABRB3 signal peptide variant is associated with autism. Mol Psychiatry. 2010; 16:8696. [PubMed: 19935738]

DeLorey TM, Handforth A, Anagnostaras SG, Homanics GE, Minassian BA, Asatourian A, et al. Mice lacking the beta3 subunit of the GABAA receptor have the epilepsy phenotype and many of 
the behavioral characteristics of angelman syndrome. J Neurosci. 1998; 18:8505-8514. [PubMed: 9763493]

DeLorey TM, Sahbaie P, Hashemi E, Homanics GE, Clark JD. Gabrb3 gene deficient mice exhibit impaired social and exploratory behaviors, deficits in non-selective attention and hypoplasia of cerebellar vermal lobules: a potential model of autism spectrum disorder. Behav Brain Res. 2008; 187:207-220. [PubMed: 17983671]

Devlin B, Scherer SW. Genetic architecture in autism spectrum disorder. Curr Opin Genet Dev. 2012; 22:229-237. [PubMed: 22463983]

Ey E, Leblond CS, Bourgeron T. Behavioral profiles of mouse models for autism spectrum disorders. Autism Res. 2011; 4:5-16. [PubMed: 21328568]

Fairless AH, Shah RY, Guthrie AJ, Li H, Brodkin ES. Deconstructing sociability, an autism-relevant phenotype, in mouse models. Anat Rec (Hoboken). 2011; 294:1713-1725. [PubMed: 21905241]

Gardener H, Spiegelman D, Buka SL. Prenatal risk factors for autism: comprehensive meta-analysis. Br J Psychiatry. 2009; 195:7-14. [PubMed: 19567888]

Gardener H, Spiegelman D, Buka SL. Perinatal and neonatal risk factors for autism: a comprehensive meta-analysis. Pediatrics. 2011; 128:344-355. [PubMed: 21746727]

Gould GG, Hensler JG, Burke TF, Benno RH, Onaivi ES, Daws LC. Density and function of central serotonin (5-HT) transporters, 5-HT1A and 5-HT2A receptors, and effects of their targeting on BTBR T+tf/J mouse social behavior. J Neurochem. 2011; 116:291-303. [PubMed: 21070242]

Guinchat V, Thorsen P, Laurent C, Cans C, Bodeau N, Cohen D. Pre-, peri- and neonatal risk factors for autism. Acta Obstet Gynecol Scand. 2012; 91:287-300. [PubMed: 22085436]

Homanics GE, DeLorey TM, Firestone LL, Quinlan JJ, Handforth A, Harrison NL, et al. Mice devoid of gamma-aminobutyrate type A receptor beta3 subunit have epilepsy, cleft palate, and hypersensitive behavior. Proc Natl Acad Sci U S A. 1997; 94:4143-4148. [PubMed: 9108119]

Jacome LF, Burket JA, Herndon AL, Deutsch SI. Genetically inbred Balb/c mice differ from outbred Swiss Webster mice on discrete measures of sociability: relevance to a genetic mouse model of autism spectrum disorders. Autism Res. 2011; 4:393-400. [PubMed: 21882363]

Kwon CH, Luikart BW, Powell CM, Zhou J, Matheny SA, Zhang W, et al. Pten regulates neuronal arborization and social interaction in mice. Neuron. 2006; 50:377-388. [PubMed: 16675393]

Lord C, Risi S, Lambrecht L, Cook EH Jr, Leventhal BL, DiLavore PC, et al. The autism diagnostic observation schedule-generic: a standard measure of social and communication deficits associated with the spectrum of autism. J Autism Dev Disord. 2000; 30:205-223. [PubMed: 11055457]

Maestrini E, Lai C, Marlow A, Matthews N, Wallace S, Bailey A, et al. Serotonin transporter (5-HTT) and gamma-aminobutyric acid receptor subunit beta3 (GABRB3) gene polymorphisms are not associated with autism in the IMGSA families. The International Molecular Genetic Study of Autism Consortium. Am J Med Genet. 1999; 88:492-496. [PubMed: 10490705]

Martin ER, Menold MM, Wolpert CM, Bass MP, Donnelly SL, Ravan SA, et al. Analysis of linkage disequilibrium in g-aminobutyric acid receptor subunit genes in autistic disorder. American Journal of Medical Genetics (Neuropsychiatric Genetics). 2000; 96:43-48. [PubMed: 10686550]

McCauley JL, Olson LM, Delahanty R, Amin T, Nurmi EL, Organ EL, et al. A linkage disequilibrium map of the 1-Mb 15q12 GABA(A) receptor subunit cluster and association to autism. Am J Med Genet B Neuropsychiatr Genet. 2004; 131:51-59. [PubMed: 15389768]

McFarlane HG, Kusek GK, Yang M, Phoenix JL, Bolivar VJ, Crawley JN. Autism-like behavioral phenotypes in BTBR T+tf/J mice. Genes Brain Behav. 2008; 7:152-163. [PubMed: 17559418]

Moy SS, Nadler JJ. Advances in behavioral genetics: mouse models of autism. Mol Psychiatry. 2008; 13:4-26. [PubMed: 17848915]

Moy SS, Nadler JJ, Perez A, Barbaro RP, Johns JM, Magnuson TR, et al. Sociability and preference for social novelty in five inbred strains: an approach to assess autistic-like behavior in mice. Genes Brain Behav. 2004; 3:287-302. [PubMed: 15344922]

Moy SS, Nadler JJ, Young NB, Nonneman RJ, Grossman AW, Murphy DL, et al. Social approach in genetically engineered mouse lines relevant to autism. Genes Brain Behav. 2009; 8:129-142. [PubMed: 19016890] 
Moy SS, Nadler JJ, Young NB, Perez A, Holloway LP, Barbaro RP, et al. Mouse behavioral tasks relevant to autism: phenotypes of 10 inbred strains. Behav Brain Res. 2007; 176:4-20. [PubMed: 16971002]

Nadler JJ, Moy SS, Dold G, Trang D, Simmons N, Perez A, et al. Automated apparatus for quantitation of social approach behaviors in mice. Genes Brain Behav. 2004; 3:303-314. [PubMed: 15344923]

Nurmi EL, Dowd M, Tadevosyan-Leyfer O, Haines JL, Folstein SE, Sutcliffe JS. Exploratory subsetting of autism families based on savant skills improves evidence of genetic linkage to 15q11-q13. J Am Acad Child Adolesc Psychiatry. 2003; 42:856-863. [PubMed: 12819446]

O'Brien SK. The validity and reliability of the Wing Subgroups Questionnaire. J Autism Dev Disord. 1996; 26:321-335. [PubMed: 8792263]

Panksepp JB, Lahvis GP. Social reward among juvenile mice. Genes Brain Behav. 2007; 6:661-671. [PubMed: 17212648]

Peca J, Feliciano C, Ting JT, Wang W, Wells MF, Venkatraman TN, et al. Shank3 mutant mice display autistic-like behaviours and striatal dysfunction. Nature. 2011

Pobbe RL, Pearson BL, Defensor EB, Bolivar VJ, Blanchard DC, Blanchard RJ. Expression of social behaviors of C57BL/6J versus BTBR inbred mouse strains in the visible burrow system. Behav Brain Res. 2010; 214:443-449. [PubMed: 20600340]

Roullet FI, Wohr M, Crawley JN. Female urine-induced male mice ultrasonic vocalizations, but not scent-marking, is modulated by social experience. Behav Brain Res. 2010

Ryan BC, Young NB, Moy SS, Crawley JN. Olfactory cues are sufficient to elicit social approach behaviors but not social transmission of food preference in C57BL/6J mice. Behav Brain Res. 2008; 193:235-242. [PubMed: 18586054]

Salmon B, Hallmayer J, Rogers T, Kalaydjieva L, Petersen PB, Nicholas P, et al. Absence of linkage and linkage disequilibrium to chromosome 15q11-q13 markers in 139 multiplex families with autism. Am J Med Genet. 1999; 88:551-556. [PubMed: 10490715]

Sankoorikal GM, Kaercher KA, Boon CJ, Lee JK, Brodkin ES. A mouse model system for genetic analysis of sociability: C57BL/6J versus BALB/cJ inbred mouse strains. Biol Psychiatry. 2006; 59:415-423. [PubMed: 16199013]

Shao Y, Cuccaro ML, Hauser ER, Raiford KL, Menold MM, Wolpert CM, et al. Fine mapping of autistic disorder to chromosome 15q11-q13 by use of phenotypic subtypes. Am J Hum Genet. 2003; 72:539-548. [PubMed: 12567325]

Silverman JL, Oliver CF, Karras MN, Gastrell PT, Crawley JN. AMPAKINE enhancement of social interaction in the BTBR mouse model of autism. Neuropharmacology. 2012

Silverman JL, Smith DG, Rizzo SJ, Karras MN, Turner SM, Tolu SS, et al. Negative allosteric modulation of the mGluR5 receptor reduces repetitive behaviors and rescues social deficits in mouse models of autism. Sci Transl Med. 2012; 4:131ra151.

Silverman JL, Yang M, Lord C, Crawley JN. Behavioural phenotyping assays for mouse models of autism. Nat Rev Neurosci. 2010; 11:490-502. [PubMed: 20559336]

Spencer CM, Alekseyenko O, Serysheva E, Yuva-Paylor LA, Paylor R. Altered anxiety-related and social behaviors in the Fmr1 knockout mouse model of fragile X syndrome. Genes Brain Behav. 2005; 4:420-430. [PubMed: 16176388]

State MW, Levitt P. The conundrums of understanding genetic risks for autism spectrum disorders. Nat Neurosci. 2011; 14:1499-1506. [PubMed: 22037497]

Veenstra-VanderWeele J, Blakely RD. Networking in autism: leveraging genetic, biomarker and model system findings in the search for new treatments. Neuropsychopharmacology. 2012; 37:196-212. [PubMed: 21937981]

Veenstra-VanderWeele J, Muller CL, Iwamoto H, Sauer JE, Owens WA, Shah CR, et al. Autism gene variant causes hyperserotonemia, serotonin receptor hypersensitivity, social impairment and repetitive behavior. Proc Natl Acad Sci U S A. 2012; 109:5469-5474. [PubMed: 22431635]

Volkmar FR, State M, Klin A. Autism and autism spectrum disorders: diagnostic issues for the coming decade. J Child Psychol Psychiatry. 2009; 50:108-115. [PubMed: 19220594]

Wing L, Gould J. Severe impairments of social interaction and associated abnormalities in children: epidemiology and classification. J Autism Dev Disord. 1979; 9:11-29. [PubMed: 155684] 
Winslow JT. Mouse social recognition and preference. Curr Protoc Neurosci. 2003; Chapter 8(Unit 816)

Winslow JT, Miczek KA. Habituation of aggression in mice: pharmacological evidence of catecholaminergic and serotonergic mediation. Psychopharmacology (Berl). 1983; 81:286-291. [PubMed: 6419256]

Wrenn CC, Harris AP, Saavedra MC, Crawley JN. Social transmission of food preference in mice: methodology and application to galanin-overexpressing transgenic mice. Behav Neurosci. 2003; 117:21-31. [PubMed: 12619904]

Yang M, Abrams DN, Zhang JY, Weber MD, Katz AM, Clarke AM, et al. Low sociability in BTBR T $+\mathrm{tf} / \mathrm{J}$ mice is independent of partner strain. Physiol Behav. 2012

Yang M, Bozdagi O, Scattoni ML, Wohr M, Roullet FI, Katz AM, et al. Reduced excitatory neurotransmission and mild autism-relevant phenotypes in adolescent Shank3 null mutant mice. $\mathrm{J}$ Neurosci. 2012; 32:6525-6541. [PubMed: 22573675]

Yang M, Clarke AM, Crawley JN. Postnatal lesion evidence against a primary role for the corpus callosum in mouse sociability. Eur J Neurosci. 2009; 29:1663-1677. [PubMed: 19419429]

Yang M, Perry K, Weber MD, Katz AM, Crawley JN. Social peers rescue autism-relevant sociability deficits in adolescent mice. Autism Res. 2011; 4:17-27. [PubMed: 20928844]

Yang M, Silverman JL, Crawley JN. Automated three-chambered social approach task for mice. Curr Protoc Neurosci. 2011; Chapter 8(Unit 8-26)

Zwaigenbaum L, Bryson S, Lord C, Rogers S, Carter A, Carver L, et al. Clinical assessment and management of toddlers with suspected autism spectrum disorder: insights from studies of highrisk infants. Pediatrics. 2009; 123:1383-1391. [PubMed: 19403506] 
A

E

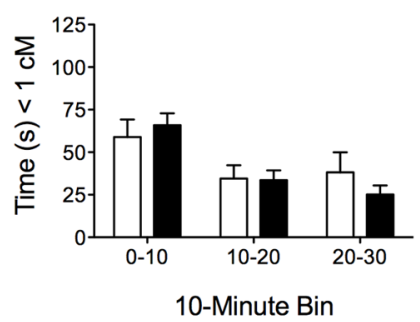

G

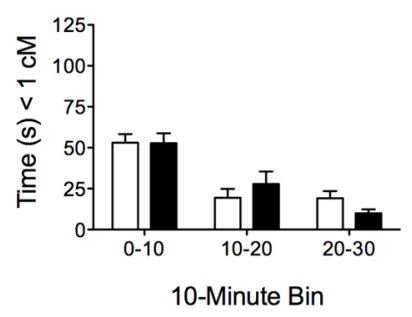

B

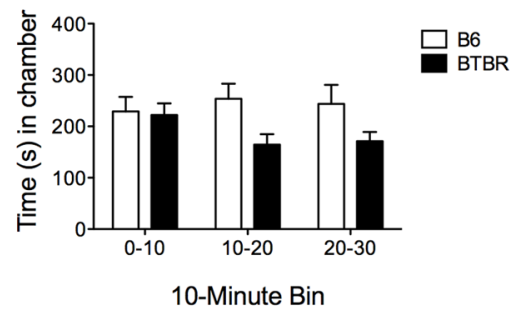

D

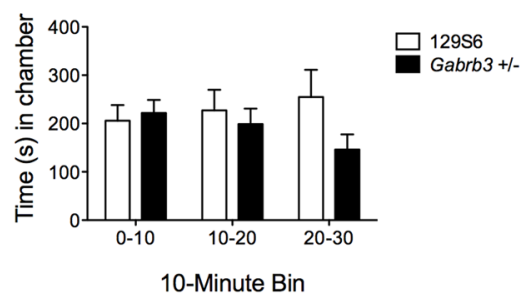

F

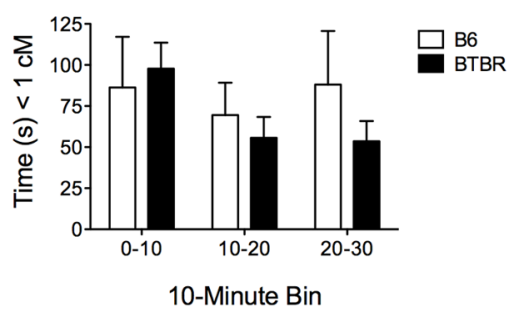

H

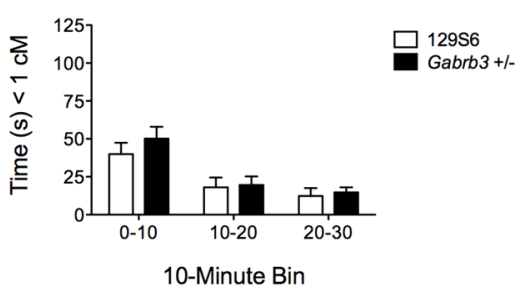

Figure 1. Preference of C57BL/6 (B6) mice for typical social interactions

A) Total time (mean, SEM) spent in the chamber containing Typical (B6, 129S6) vs. Atypical (BTBR, BALB/c, Gabrb3 +/-) stimulus mice (Two-way, repeated-measures ANOVA, strain $\mathrm{x}$ time interaction $\mathrm{F}=10.99, \mathrm{P}<0.0001 ; \mathrm{n}=30)$. B) B6 vs. BTBR (interaction $\mathrm{F}=1.75, \mathrm{P}=0.19$; Strain $\mathrm{F}=4.46, \mathrm{P}=0.051 ; \mathrm{n}=10$ ). $\mathrm{C}$ ) $129 \mathrm{~S} 6$ vs. BALB/c (interaction F $=9.01, \mathrm{P}=0.0007 ; \mathrm{n}=10$ ). D) $129 \mathrm{~S} 6$ vs. Gabrb3 +/- (interaction F = 3.76, P $=0.033 ; \mathrm{n}=10)$. E) Time spent within $1 \mathrm{~cm}$ of the inverted pencil cup containing Typical (B6, 129S6) vs. Atypical (BTBR, BALB/c, Gabrb3+/-) stimulus mice (interaction F = 3.53, $\mathrm{P}=0.033 ; \mathrm{n}=30$ ). $\mathrm{F}$ ) $\mathrm{B} 6$ vs. BTBR (interaction $\mathrm{F}=2.48, \mathrm{P}=0.10 ; \mathrm{n}=10$ ). $\mathrm{G}$ ) $129 \mathrm{~S} 6$ vs. $\mathrm{BALB} / \mathrm{c}$ (interaction $\mathrm{F}=2.37, \mathrm{P}=0.11 ; \mathrm{n}=10$ ). $\mathrm{H}$ ) $129 \mathrm{~S} 6$ vs. Gabrb3 $+/-($ interaction $\mathrm{F}=$ $0.77, \mathrm{P}=0.47 ; \mathrm{n}=10)$. Bonferroni multiple comparison test run on significant interactions: $* \mathrm{P}<0.05, * * \mathrm{P}<0.01, * * * \mathrm{P}<0.001$. 
A

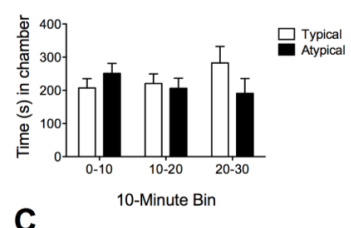

C

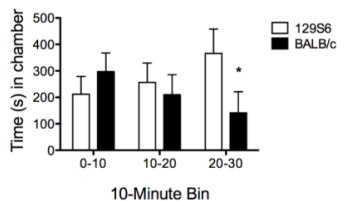

E

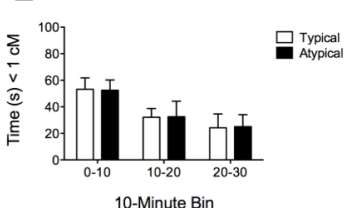

G

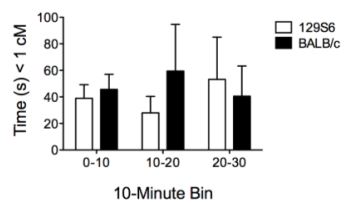

B

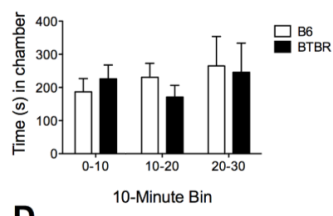

D

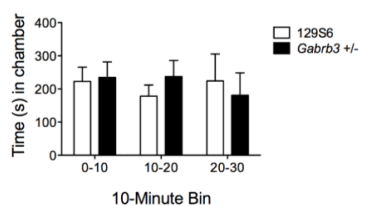

$\mathbf{F}$

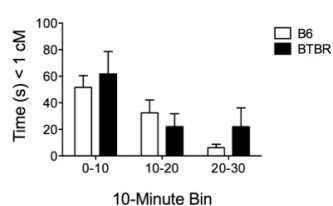

H

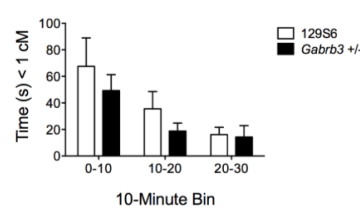

Figure 2. Preference of 129S6/SvEvTac (129S6) mice for typical social interactions

A) Total time (mean, SEM) spent in the chamber containing Typical (B6, 129S6) vs. Atypical (BTBR, BALB/c, Gabrb3+/-) stimulus mice (Two-way, repeated-measures ANOVA, Strain $\mathrm{x}$ time interaction $\mathrm{F}=3.49, \mathrm{P}=0.034, \mathrm{n}=30$ ). B) $\mathrm{B} 6$ vs. BTBR stimulus mice (interaction $\mathrm{F}=0.49, \mathrm{P}=0.62 ; \mathrm{n}=10$ ). $\mathrm{B}$ ) $129 \mathrm{~S} 6 \mathrm{vs}$. $\mathrm{BALB} / \mathrm{c}$ (interaction $\mathrm{F}=7.52, \mathrm{P}$ $=0.0021 ; \mathrm{n}=10)$. C) $129 \mathrm{~S} 6$ vs. Gabrb3 $+/-($ interaction $\mathrm{F}=0.80, \mathrm{P}=0.46 ; \mathrm{n}=10)$. D) Pooled Typical (B6, 129S6) vs. Atypical (BTBR, BALB/c, Gabrb3 +/-) (interaction F = $3.49, \mathrm{P}=0.034 ; \mathrm{n}=30)$. E) Time spent within $1 \mathrm{~cm}$ of the inverted pencil cup containing Typical (B6, 129S6) vs. Atypical (BTBR, BALB/c, Gabrb3 +/-) stimulus mice (interaction $\mathrm{F}=0.0072, \mathrm{P}=0.99$ ). $\mathrm{F}$ ) $\mathrm{B} 6$ vs. $\mathrm{BTBR}$ (interaction $\mathrm{F}=1.78, \mathrm{P}=0.18 ; \mathrm{n}=10$ ). $\mathrm{G}) 129 \mathrm{~S} 6$ vs. $\mathrm{BALB} / \mathrm{c}$ (interaction $\mathrm{F}=0.83, \mathrm{P}=0.44 ; \mathrm{n}=10$ ). $\mathrm{H}$ ) $129 \mathrm{~S} 6$ vs. Gabrb3 $+/-$ (interaction $\mathrm{F}=$ $0.36, \mathrm{P}=0.70 ; \mathrm{n}=10$ ). Bonferroni multiple comparison test run on significant interactions: $* \mathrm{P}<0.05$. 